\title{
Hematopoietic stem cell transplantation: a primer for the primary care physician
}

\section{Chantal S. Léger, Thomas J. Nevill}

\section{Abstract}

HeMATOPOIETIC STEM CELL TRANSPLANTATION has been used for many years to treat various malignant and nonmalignant hematologic conditions. However, the high-dose conditioning regimen can lead to major organ dysfunction, life-threatening infection and bleeding. In the allogeneic setting, graft-versus-host disease may also develop, making post-transplant management complex. Once a transplant recipient is discharged from hospital and returns to his or her local community, the primary care physician can play an important role in care. Recipients of stem cell transplants may be severely immunocompromised for many months after transplantation, especially if they are still taking immunosuppressive drugs. Furthermore, endocrine and metabolic deficiencies can develop, and transplant survivors are at risk of a second malignant disease. This review is intended as a basic overview of allogeneic and autologous stem cell transplantation with a special focus on longterm follow-up issues relevant to primary care providers.

CMAJ 2004;170(10):1569-77

$\mathrm{B}$ one marrow transplantation was first attempted, albeit unsuccessfully, in 1939, when human bone marrow cells were injected intravenously to treat a patient with aplastic anemia. ${ }^{1,2}$ Since that time, despite uneven progress and problems with entities such as graft-versushost disease (GVHD), ${ }^{3,4}$ the procedure has become an accepted treatment for various hematologic deficiencies and malignant conditions.

Stem cell transplantation can be performed with cells from a family member or an unrelated volunteer (allogeneic transplantation) or with stem cells previously collected from the patient (autologous transplantation). The choice between the more risky allogeneic transplant and an autologous procedure depends on patient age, the underlying disease, donor availability and institutional preference (Box 1). The drawbacks of an autologous transplant are possible contamination of the graft with malignant cells and the lack of a graft-versus-tumour effect (see "Immunoreconstitution: a double-edged sword"). Allogeneic transplantation represents $40 \%$ of all stem cell transplants performed annually in Canada and requires donor and recipient matching for major histocompatibility (HLA) antigens. The best donor is an HLA-identical sibling; ${ }^{5}$ transplants with only partial matching for HLA antigens are associated with a higher risk of post-transplant complications. Because only $25 \%$ of patients have a suitable sibling donor, an International Unrelated Donor Registry of over 7 million healthy volunteers has been created. ${ }^{6}$ At present, a satisfactory unrelated donor can be identified for $80 \%$ of white patients, but this figure is lower for patients in other ethnic groups. ${ }^{6}$

Because of the requirement for highly trained medical staff, stem cell transplantation is performed only at specialized centres. Although stem cells can be collected by direct aspiration from the bone marrow, with the patient under general or spinal anesthetic (Fig. 1), they are now more commonly harvested from the peripheral blood. Blood stem cell transplantation is accomplished by treating the donor with hematopoietic growth factors, which cause the stem cells to proliferate and circulate freely in the peripheral blood. The blood is then collected by venipuncture and subjected to leukapheresis to obtain the cells for transplantation. ${ }^{7}$ The use of blood stem cells is associated with faster recovery of neutrophils and platelets after transplantation (engraftment) than is the case with bone marrow stem cells. ${ }^{8,9}$ Umbilical cord blood harvested at the time of delivery is also used for this purpose..$^{10,11}$

Box 1: Common indications for hematopoietic stem cell transplantation

Allogeneic

- Acute leukemia

- Myelodysplastic syndrome

- Chronic myeloid leukemia

- Severe aplastic anemia

- Indolent lymphoma

- Chronic lymphocytic leukemia

- Severe immunodeficiency syndromes

- Hemoglobinopathies

Autologous

- Progressive large-cell lymphoma

- Progressive Hodgkin's disease

- Multiple myeloma

- Relapsed germ cell tumour 


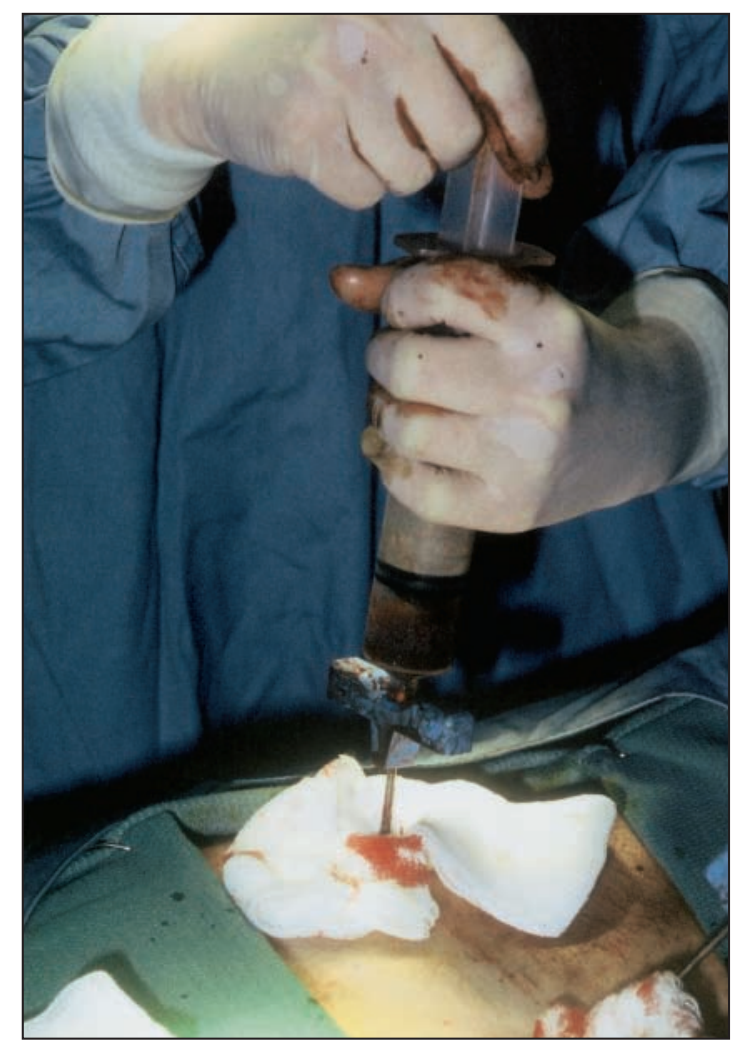

Fig. 1: Collection of stem cells by direct aspiration from bone marrow, with the donor under general anesthetic.
The actual transplantation of the cells is a simple process involving intravenous infusion of a liquid stem cell product through a large-bore central venous catheter over 1 to 2 hours. The stem cells are then able to travel or "home" to the bone marrow cavity to re-establish hematopoiesis over the next 2 weeks. ${ }^{12}$ It is the care of the patient after transplantation that can present much more of a challenge to the multidisciplinary care team, especially in the setting of allogeneic transplant. In this article we aim to familiarize primary care practitioners with some of the basics of allogeneic and autologous transplantation, as well as issues relevant to the care of transplant recipients over the short and the long term.

\section{Allogeneic transplantation}

This section describes the 4 components of allogeneic transplantation - conditioning, transplantation, engraftment and immunoreconstitution (Fig. 2) - and provides information about the patient's hospital stay and the risks associated with this type of transplantation.

\section{The conditioning regimen: destroying the disease}

In preparation for allogeneic stem cell transplantation, the recipient undergoes a conditioning regimen of highdose chemotherapy and, in some cases, radiotherapy to eradicate the underlying malignant disease and to suppress

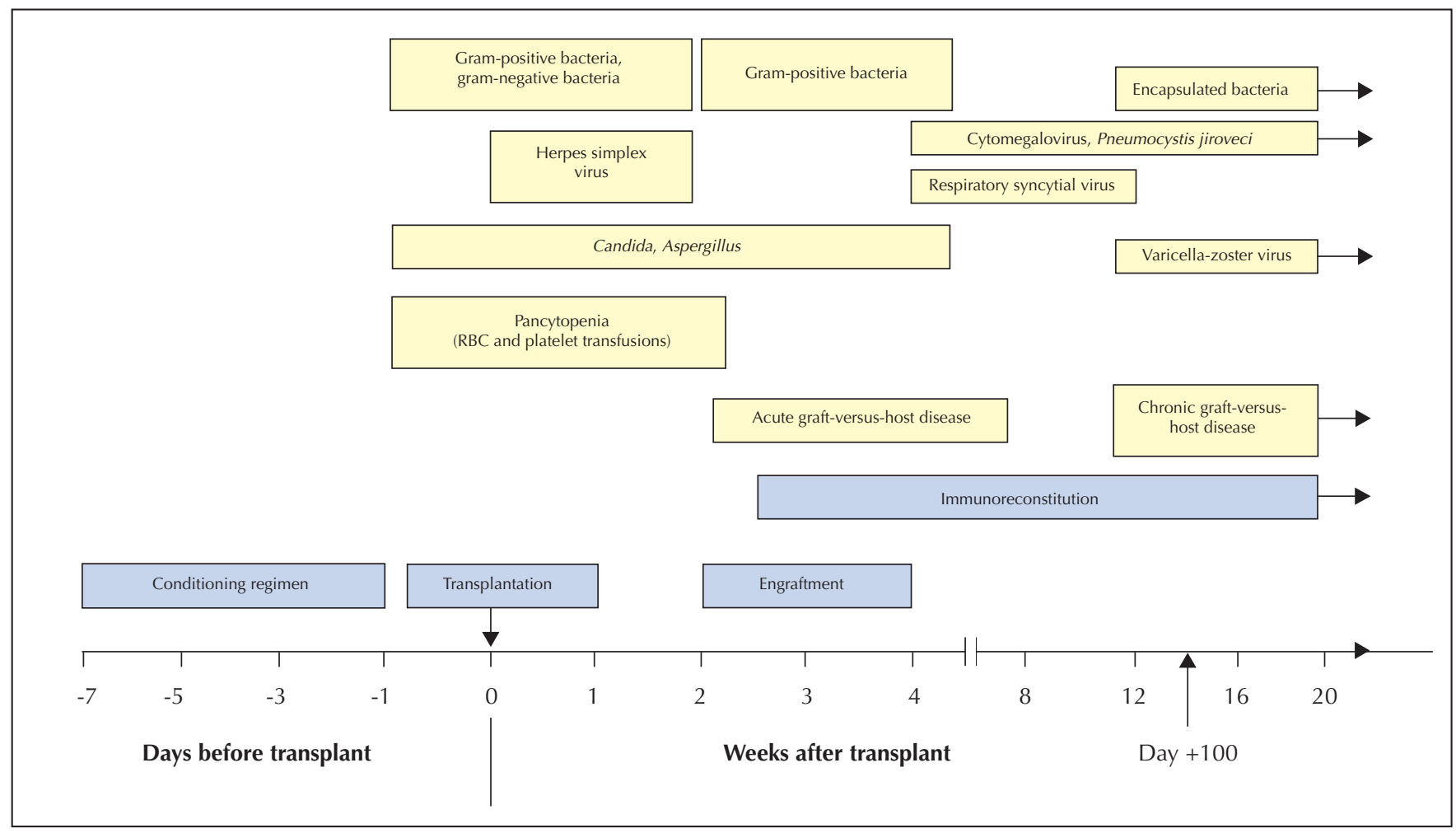

Fig. 2: Course of events and risks associated with allogeneic transplantation. Blue boxes represent the 4 components of transplantation as outlined in the text; yellow boxes represent the various risks at different stages. RBC $=$ red blood cells. 
the recipient's immune system so that it will not reject the donor's stem cells.

The first conditioning regimen to be developed - highdose cyclophosphamide combined with total body irradiation (TBI) - remains in common use, ${ }^{13}$ and a variety of other TBI and non-TBI preparative regimens have also been developed. ${ }^{14}$ Conditioning is administered over approximately 1 week and produces both hematologic (pancytopenia) and nonhematologic side effects. The latter, referred to collectively as regimen-related toxicity, ${ }^{15}$ can affect many organ systems (Box 2), but painful oropharyngeal mucositis is especially difficult for the patient (Fig. 3 ) and may necessitate continuous infusion of narcotics and total parenteral nutrition.

\section{Transplantation: countdown to day 0}

By convention, pretransplant conditioning days are numbered in a countdown fashion, from day -7 to day 0 (the actual date of transplantation). The days after transplantation are then numbered upward, such that 10 days after the transplant would be day +10 . This universal system is useful for describing the timing of events, such as engraftment.

From day 0 until engraftment, the patient's protective immunity is reduced, and he or she is vulnerable to infection. In part, this vulnerability is due to breaks in the natural mucosal and skin barriers secondary to mucositis and the necessary indwelling central venous catheter, but neutropenia and other immunodeficiencies also contribute to the risk. Febrile neutropenia, an expected occurrence, requires prompt treatment with broad-spectrum antibiotics. In addition, all patients routinely receive antifungal and antiviral prophylaxis. ${ }^{16}$

Throughout the neutropenic period, the patient is confined to a single room equipped to provide the safest possible environment. A positive-pressure room equipped with high-efficiency particulate air (HEPA) filters remains the "industry standard." Although a strict hand-washing protocol is mandatory, gowns, gloves and masks are rarely required. Restriction to an isolation room is physically and emotionally difficult for patients, and many experience a feeling of isolation, which compounds their natural anxiety. ${ }^{17}$

\section{Engraftment: stem cell function begins}

Engraftment is the process whereby the donor cells begin to produce new blood components within the recipient's bone marrow cavity. In practice, engraftment is said to have occurred when the absolute neutrophil count consistently exceeds $0.5 \times 10^{\circ} / \mathrm{L}$. Platelet and red blood cell engraftment generally follows. The patient is supported with blood products until engraftment occurs. Engraftment usually occurs between day +10 and day +20 and is earlier (within this range) when blood stem cells, rather than bone marrow cells, are used. ${ }^{8,9}$ Failure to engraft (primary graft failure or graft rejection) and subsequent irreversible decline of blood counts (secondary graft failure) are serious complications. Fortunately, these conditions develop in less than $5 \%$ of recipients, and they are particularly rare after matched-sibling transplant. ${ }^{18}$

\section{Immunoreconstitution: a double-edged sword}

Restoration of T-cell and B-cell immunity, which may take 12 months or longer, is critical to the recipient's recovery process. ${ }^{19}$ It is only when the donor's immune system is fully functional within the recipient that the risk of opportunistic infection decreases to premorbid levels. However, the presence of immunocompetent donor $\mathrm{T}$ cells can also lead to the recognition of host tissue as foreign and hence the development of GVHD. ${ }^{20}$

GVHD is classified as acute when it occurs in the first 100 days after transplantation and chronic when it persists or develops after day +100 (see "Chronic GVHD"). Clinically significant acute GVHD occurs in about $40 \%$ of matched-sibling and $80 \%$ of unrelated-donor transplant recipients. Acute GVHD is characterized by a rash (Fig. 4), hepatic dysfunction, diarrhea and vomiting. Certain patients are at greater risk (Box 3). Grade III and IV acute GVHD is associated with a mortality rate of $80 \%,{ }^{21}$ although many of these deaths are due to superimposed infection, as a result of both the immunosuppressive effects of GVHD and the medications used to treat the condition (cyclosporine, corticosteroids and antithymocyte globulin). ${ }^{22}$ Administration of GVHD prophylaxis is standard practice for transplants involving anyone other than identical twins; a combination of methotrexate and cyclosporine is commonly used. The graft 
can also be manipulated to deplete the T-lymphocyte population, but this is associated with a higher risk of infection, graft failure and relapse. ${ }^{23}$ If GVHD occurs, it is initially treated with high-dose corticosteroid therapy, which results in a satisfactory response in $50 \%$ to $75 \%$ of patients. Despite the morbidity and mortality associated with GVHD, its presence may be desirable in some situations because of its association with a lower risk of recurrence of the malignant disease (graft-versus-tumour effect). ${ }^{24}$

\section{The hospital stay and beyond}

The average length of hospital stay for allogeneic transplantation is 5 weeks, but the stay can be much longer if complications develop. Furthermore, 25\% of patients require at least one readmission during the first 3 months after transplantation. After discharge, the patient's care is continued through the daycare unit, where visits are required for blood work (to assess graft function, late regimen-related toxicity and GVHD), transfusion support and administration of prophylactic antimicrobials.

\section{Risks}

Treatment-related mortality in the first 12 months after matched-sibling stem cell transplantation is about $20 \%$ to $30 \% .{ }^{25}$ The figure is higher among recipients of an allograft from an unrelated donor, reaching almost $50 \%$ at most adult transplant centres. ${ }^{25}$ Patients who do not succumb to transplant-related complications may still have a recurrence of their underlying malignant disease, almost always within the first 2 years after the transplant. The risk of relapse depends on the status of disease at the time of transplantation, but even acute leukemia in first complete remission recurs in $25 \%$ of patients. ${ }^{26}$

\section{Autologous transplantation}

The rationale for autologous transplantation is that cryopreservation of the patient's own stem cells allows delivery of high-dose chemotherapy and radiotherapy that would otherwise produce lethal bone marrow suppression. The

\section{Box 3: Risk factors for acute graft-versus-host disease (GVHD)}

- HLA mismatch between donor and recipient

- Use of an unrelated donor

- Older age of recipient or donor (or both)

- Donor allosensitization by pregnancy or transfusion

- Sex mismatch between donor and recipient

- Use of T-cell-replete graft

- Severe regimen-related toxicity

- Compromised delivery of GVHD prophylaxis*

Note: HLA = human leukocyte antigen.

* If the patient has renal or liver dysfunction or severe mucositis, the dose of medication may be reduced to minimize any toxic effects.

first 3 phases of autologous transplantation are similar to those described above for allogeneic transplantation, except the donor and recipient are the same person. The fourth phase differs, in that the patient's immune recovery is more rapid and there is no potential for GVHD.

Before the collection of autologous stem cells, the patient is usually given chemotherapy to debulk the malignant disease. Thereafter, further chemotherapy or stem cell growth factor (granulocyte colony-stimulating factor) is given to stimulate the stem cells to leave the bone marrow and enter the peripheral blood. ${ }^{27}$ The patient then undergoes 1 or 2 (sometimes 3 ) leukapheresis procedures during which 10 to $20 \mathrm{~L}$ of blood are processed; the component containing the stem cells is cryopreserved until it is needed for re-infusion on day 0 .

Although stem cells can remain viable after many years of cryopreservation, in practice the patient begins the conditioning regimen within a few days to a few weeks after their collection. As with allogeneic transplantation, conditioning takes about 1 week, after which the cryopreserved stem cells are thawed and infused intravenously (Fig. 5). Because immunoreconstitution occurs more quickly than with allografting, autologous transplantation is better toler-
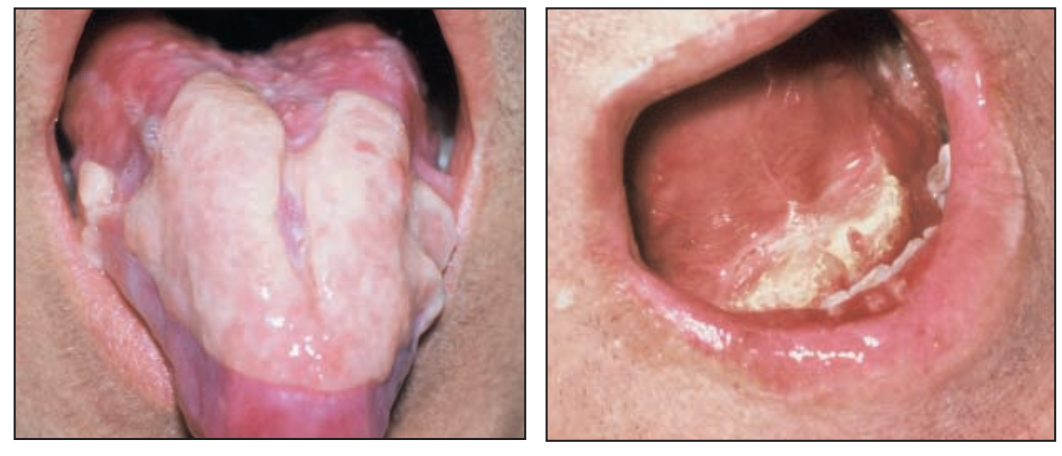

Fig. 3: Oropharyngeal mucositis, which may occur as a result of conditioning before stem cell transplantation.

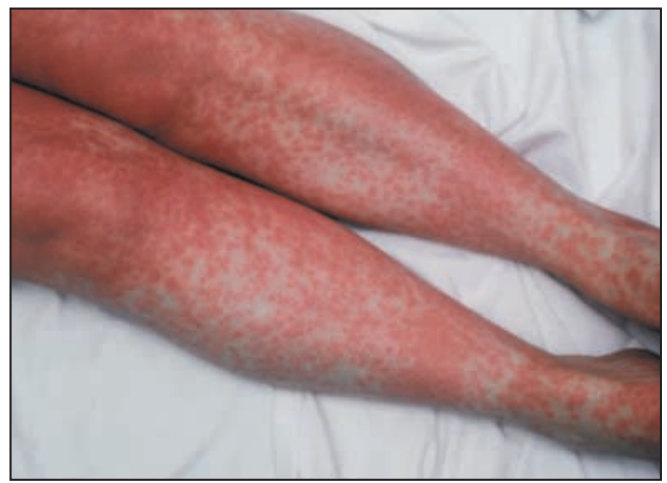

Fig. 4: Rash of graft-versus-host disease. 
ated by patients (transplant-related mortality at day +100 is only $5 \%$ to $10 \%) .{ }^{25}$ This in turn allows autologous transplantation to be performed in older patients, ${ }^{28}$ and some patients are well enough to receive part or all of their treatment in the outpatient setting..$^{29}$ Even when admission to hospital is required for autologous transplantation, the stay rarely exceeds 3 weeks.

\section{Long-term follow-up}

During the initial 3 months after transplantation, recipients are assessed a minimum of once weekly in the outpatient transplant clinic. Thereafter, long-term survivors without serious complications are seen in the specialty clinic every 3 to 6 months. At this point, the primary care physician begins to play a crucial role in long-term care. The family physician needs to be aware that organ damage from the conditioning regimen, chronic GVHD (see specifics in next column) and immunosuppressive drugs may all lead to an ongoing risk of complications. Infections are of particular concern in allogeneic transplant recipients, may be more severe than in otherwise healthy patients and can involve unusual (or opportunistic) organisms. The use of immunosuppressive agents for many months or years

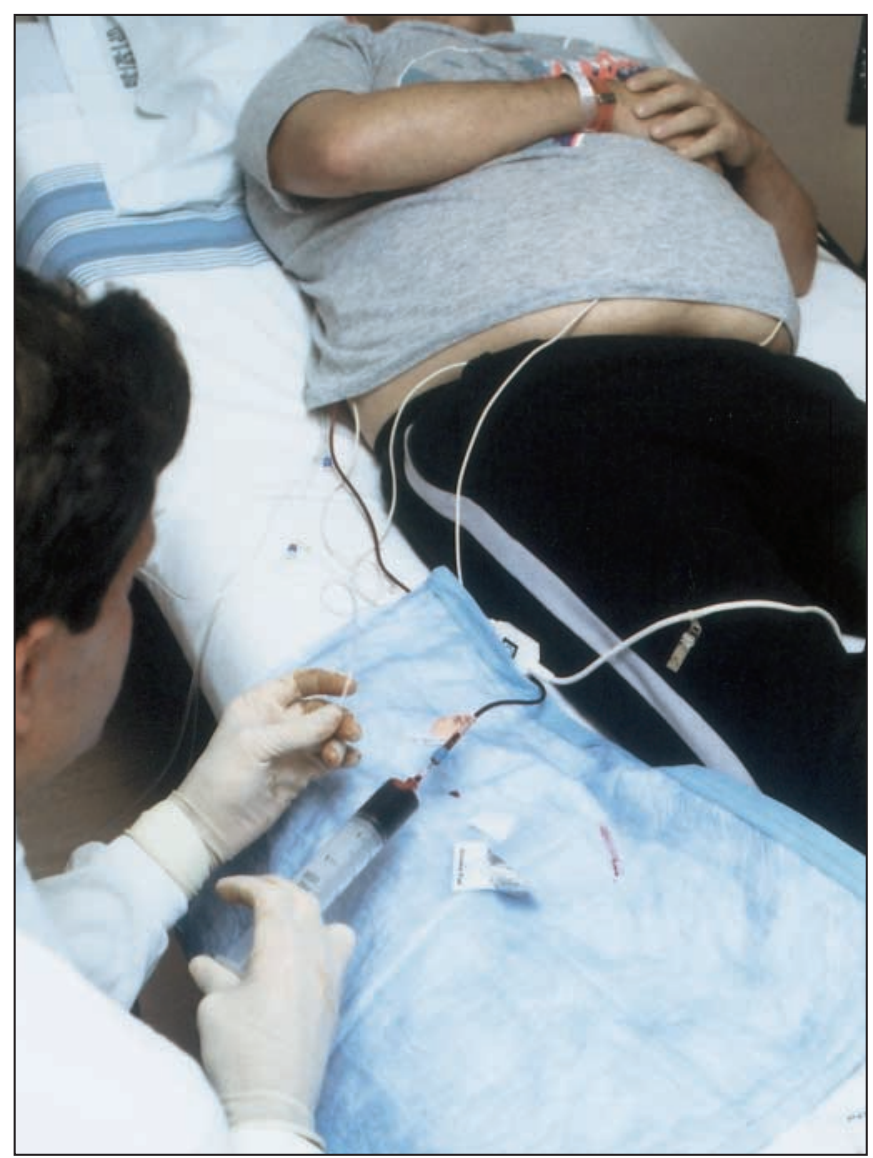

Fig. 5: Patient receiving infusion of autologous stem cell preparation. can also predispose allogeneic transplant survivors to a multitude of additional health problems (Box 4). With these factors in mind, recommendations for follow-up care of all stem cell transplant recipients are listed in Box 5 .

\section{Chronic GVHD}

Chronic GVHD is a syndrome unique to allogeneic stem cell transplantation, with manifestations resembling those seen in autoimmune disease (Fig. 6). The highly variable findings may include oral and ocular changes (sicca syndrome), cholestatic hepatic dysfunction and cutaneous scleroderma (Box 6).$^{30}$ Chronic GVHD occurs in at least half of HLA-identical sibling transplants, and its presence is a major risk factor for infection. ${ }^{31}$ Treatment of chronic GVHD usually begins with a combination of corticosteroids and cyclosporine for a minimum of 6 months, with the use of immunosuppressive drugs further increasing the risk of infectious complications. ${ }^{32}$

\section{Box 4: Potential medical complications of long-term immunosuppressive therapy}

- Osteopenia or osteoporosis

- Avascular necrosis

- Hips

- Shoulders

- Knees

- Hypertension

- Diabetes mellitus

- Hyperlipidemia

- Accelerated atherosclerotic vascular disease

- Renal insufficiency

- Predisposition to infection

- Bacterial

- Viral

- Opportunistic

- Renal insufficiency

- Myopathy

- Second malignant disease

- Lymphoma

- Other

- Depression

- Cosmetic changes

- Obesity

- Hirsutism

- Acne

- Skin striae 


\section{Infections, vaccinations and safe living after transplantation}

Although patients surviving for 10 years or more after transplantation have near-normal immunity, ${ }^{33}$ persistent hypogammaglobulinemia, impaired cellular immunity and splenic hypofunction all contribute to an increased risk of infection for up to 5 years after transplantation, especially in allogeneic transplant recipients with chronic GVHD. ${ }^{34}$ Recurrent sinopulmonary infections (e.g., sinusitis, pneumonia, bronchitis) are common in the first 2 years after any stem cell transplant, and reactivation of latent varicellazoster virus occurs in almost $50 \%$ of survivors. The reactivation typically presents as a crusting vesicular dermatomal rash (shingles) 6 to 12 months after transplantation. ${ }^{35}$ Prompt treatment with oral antiviral drugs may limit postherpetic neuralgia and can prevent more serious dissemination of disease. ${ }^{36}$ Reactivation of cytomegalovirus (CMV),

\section{Box 5: Recommendations for follow-up care of stem cell transplant recipients}

- Assess for chronic GVHD (see Box 6) every 3 months*

- Complete dental examination every 6 months

- Complete annual physical examination

- Prostate examination (may include determination of PSA level) (from age 30)

- Breast examination and mammography (from age 30)

- Pelvic examination and Papanicolaou smear

- Thyroid examination

- Skin examination for premalignant or malignant change

- Screening for colorectal cancert

- Ophthalmologic examination

- Complete and differential blood count, creatinine level, liver function, TSH level, cholesterol level

- Serum immunoglobulin levels* $\neq$

- Chest radiography

- Bone densitometry

- Assess for menopausal symptoms (may include determination of FSH and LH levels)

- Assess for cardiac risk factors (may include exercise treadmill test, as needed)

Note: PSA = prostate-specific antigen, TSH = thyroid-stimulating hormone, $\mathrm{FSH}=$ follicle-stimulating hormone, $\mathrm{LH}=$ luteinizing hormone. *For allogeneic transplant recipients.

tAt a minimum, to include digital rectal examination and stool examination for occult blood.

$\neq$ Discontinue when patient has been off immunosuppressive drugs for 12 months. most common in allogeneic recipients who are taking corticosteroids for GVHD, can also be life-threatening. Prophylactic ganciclovir is usually administered to CMVantibody-positive patients who require corticosteroid treatment during the first 3 to 6 months after allogeneic transplantation. ${ }^{37}$ Pneumocystis jiroveci (formerly carinii) pneumonia can occur in both autologous and allogeneic recipients, and prophylaxis with trimethoprim-sulfamethoxazole or intravenously administered pentamidine is usually recommended until 3 months after transplantation for autologous recipients and until discontinuation of all immunosuppressive drugs in the allogeneic setting. ${ }^{38}$

Antibody titres to vaccine-preventable diseases decline during the first 4 years after transplantation; this decline cannot be prevented by pretransplantation vaccination of either an allogeneic donor or a transplant recipient. ${ }^{39,40} \mathrm{Re}-$ cipients are usually immunocompetent by 2 years after transplantation, and many can begin revaccination as early as 1 year after transplantation. Vaccinations are not suggested (and live vaccines are contraindicated) for allogeneic transplant recipients who are receiving immunosuppressive drugs and those with active chronic GVHD. ${ }^{16}$ Recommended guidelines for vaccination of patients after allogeneic and autologous stem cell transplantation are presented in Table 1.

Safe-living practices are a common concern for transplant survivors. Food preparation should be meticulous (including washing hands with soap before and after handling food, using separate utensils for cutting meats and other foods, and careful refrigeration of perishable foods), consumption of fresh water should be avoided and sexual practices may need to be modified during the immunoreconstitution phase. ${ }^{16}$ Travel to developing countries is not recommended during the first 2 years after transplantation. Although pets are not strictly prohibited, steps should be taken to minimize contact with the animal's saliva or excrement (e.g., patients should avoid changing litter boxes or cleaning bird cages). ${ }^{16}$

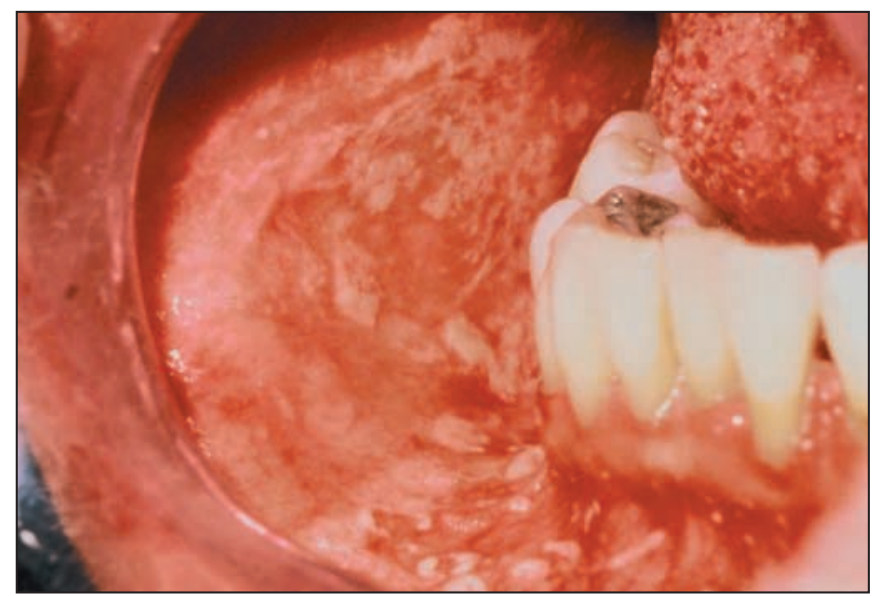

Fig. 6: Oral lichenoid mucosal reaction and periodontal disease, occurring as part of graft-versus-host disease. 


\section{Fertility}

Counselling about fertility has become an important issue, given improvements in survival after stem cell transplantation. Infertility in both men and women is the rule after conditioning with TBI-based regimens. ${ }^{41}$ Pregnancy has been reported, if rarely, in women who have undergone TBI; however, in one study, 6 (37\%) of 16 pregnancies that occurred in 13 TBI recipients terminated in spontaneous abortion. ${ }^{42}$ Although generally not occurring until a number of years after transplantation, recovery of spermatogenesis has also been reported in a minority of men treated with TBI. ${ }^{43}$ Counselling of patients who have received non-TBI conditioning is less well defined, since preservation of fertility is possible, ${ }^{44}$ even likely, when cyclophosphamide alone is used for patients with aplastic anemia. Contraception should be discussed with the patient as necessary; the younger a female patient is at the time of transplantation, the higher the possibility of a successful pregnancy after high-dose chemotherapy or radiotherapy..$^{45}$ One study found a $25 \%$ incidence of preterm labour and low-birthweight infants among women who had undergone marrow transplantation but no increased risk of congenital anomalies. ${ }^{42}$ Semen analysis in male patients and measurement of follicle-stimulating hormone and luteinizing hormone levels in women can be performed to determine menopausal status and the potential for recovery of fertility.

\section{Second malignant disease}

Solid cancers are more common in patients who have undergone either autologous or allogeneic stem cell transplantation than in the general population. ${ }^{46,47}$ In patients who have undergone autologous transplantation, greater risks of myelodysplastic syndrome/acute myelogenous leukemia (MDS/AML), lymphoproliferative disorders and solid tumours have all been observed. ${ }^{48}$ Although MDS/ AML is not a common problem for allogeneic transplant recipients, the observed-to-expected ratio for solid tumours at 10 years was 8.3. ${ }^{46}$ The observed-to-expected ratio is significantly greater than that in the general population for cancers of the bone (13.4), oropharynx (11.1), connective tissue (8.0), central nervous system (7.6), liver (7.5) and thy- roid (6.6) and for malignant melanoma (5.0). ${ }^{46}$ The lifetime risk of a solid tumour is highest among young patients who have received TBI-containing conditioning. These studies highlight the importance of regular screening of all stem cell transplant survivors for the development of a second malignant disease (Box 5).

\section{Long-term survival}

Information on long-term survival and late deaths in 6700 allogeneic transplant recipients has been reported by the International Bone Marrow Transplant Registry. ${ }^{47}$ This study found that, for many years after transplantation, the mortality rate in this group was higher than that in the general population, mainly because of recurrent leukemia and complications related to chronic GVHD. Secondary graft failure usually occurs within the first 6 months after transplantation, but very late graft rejection has been reported and may herald disease relapse. ${ }^{18}$

Although GVHD is not an issue for autologous transplant recipients, these patients may also experience late complications. Progressive restrictive lung disease, premature atherosclerotic heart disease and endocrine deficiencies have all been reported in survivors of autologous transplantation. ${ }^{49}$ Furthermore, although relapse usually occurs within the first 2 years after transplantation, it has been observed up to 8 years later.

In long-term follow-up studies, the vast majority of transplant survivors have reported good performance status. In allogeneic recipients, the presence or absence of significant chronic GVHD is the main determinant of performance status. In all survivors of stem cell transplantation, fatigue and sexual dysfunction are common complaints, with fear of relapse and supportive care medications being contributing factors. ${ }^{49-51}$ Physicians caring for survivors need to be aware of these complex medical and psychological issues in order to provide the support required.

\section{Recent developments: cord blood and "mini" transplants}

Over the past 2 decades, significant medical advances have led to a reduction in morbidity and mortality among 
recipients of stem cell transplants, and new techniques have further increased the recipient pool. The successful transplantation of unrelated umbilical cord blood cells from central storage facilities was one of the most exciting developments of the 1990s. Part of the interest in umbilical cord blood as a stem cell product is the fact that, before its widespread collection for cryopreservation and banking, it had no known use and was usually discarded. However, cord blood provides an essentially unlimited supply of donors, and these donors appear to possess an immature (and therefore more tolerant) immune system, which allows for a greater degree of mismatching between donor and recipient. ${ }^{10,11} \mathrm{~A}$ drawback to cord blood transplantation is that the number of stem cells in the product is relatively low for a large recipient (e.g., an older child or an adult). As a result, the vast majority of successful cord blood transplants have been done in small children; nonetheless, some adults have become long-term survivors. ${ }^{52}$

In the late 1990s, investigators at the MD Anderson Cancer Center reported success with a new stem cell transplantation procedure referred to as a non-myeloablative or "mini" transplant. ${ }^{53}$ This procedure uses a mild conditioning regimen that is more tolerable for older patients and those with concurrent illnesses. The goal of this approach is not to destroy the patient's cancer with the usual highdose treatment but rather to suppress the recipient's immune system enough to allow a donor's stem cells to en-

\section{Table 1: Vaccination schedule for recipients of hematopoeitic stem cell transplants}

\begin{tabular}{lccc}
\hline & \multicolumn{3}{c}{ Time after transplantation } \\
\cline { 2 - 4 } Vaccine & $12 \mathrm{mo}$ & $14 \mathrm{mo}$ & $24 \mathrm{mo}$ \\
\hline Inactivated vaccine or toxoid & & & \\
Tetanus-diphtheria toxoid* & $\sqrt{ }$ & $\sqrt{ }$ & $\sqrt{ }$ \\
Hemophilus influenzae b & $\sqrt{ }$ & $\sqrt{ }$ & $\sqrt{ }$ \\
Hepatitis B $\dagger$ & $\sqrt{ }$ & $\sqrt{ }$ & $\sqrt{ }$ \\
23-valent pneumococcal & & & \\
polysaccharide & $\sqrt{ }$ & $\mathrm{NA}$ & $\sqrt{ }$ \\
Influenzał & Seasonal & Seasonal & Seasonal \\
Inactivated polio & $\sqrt{ }$ & $\sqrt{ }$ & $\sqrt{ }$ \\
Hepatitis A & $\mathrm{NI}$ & $\mathrm{NI}$ & $\mathrm{NI}$ \\
Meningococcus & $\mathrm{NI}$ & $\mathrm{NI}$ & $\mathrm{NI}$ \\
Live-attenuated vaccine & & & \\
Measles-mumps-rubella $\$$ & $\mathrm{Cl}$ & $\mathrm{Cl}$ & $\sqrt{ }$ \\
Varicella vaccine & $\mathrm{Cl}$ & $\mathrm{Cl}$ & $\mathrm{Cl}$ \\
\hline
\end{tabular}

Note: $\mathrm{NI}=$ not indicated, $\mathrm{NA}=$ not applicable $\mathrm{Cl}=$ contraindicated.

Reprinted, with modifications, from Biology of Blood and Marrow Transplantation $(2000 ; 6: 659-734),{ }^{16}$ with permission of the American Society for Blood and Marrow Transplantation.

*After the first 2 years, recipients should be revaccinated with tetanus-diphtheria toxoid every 10 years.

†Recommended because patients may require transfusion support in the future.

¥Lifelong, seasonal administration is recommended, beginning before transplantation and resuming at some point more than 6 months after transplantation.

$\S U$ se of live vaccines is indicated only for immunocompetent patients. The first dose of measles-mumps-rubella vaccine is given at 24 months, and the second dose is recommended 6-12 months later.

I To protect the transplant recipient from varicella exposure, all varicella-susceptible close contacts of the recipient should be vaccinated against varicella. graft and slowly generate a "graft-versus-tumour effect." Mini-transplants are now in widespread use, and although their potential to cure some malignant diseases is supported by relatively short-term follow-up, it is clear that the procedure is not without risk. Further investigation of minitransplants is required before their role in stem cell transplantation for the treatment of hematologic disease can be defined.

\section{Conclusions}

Hematopoietic stem cell transplantation is commonly used for the treatment of hematologic malignant disease. Primary care physicians should be aware of the potential complications of the procedure. Many changes in stem cell transplantation have occurred over the past 3 decades, and further refinement will occur. Up-to-date information for physicians, patients and donors is available through the Web site of the Leukemia/Bone Marrow Transplant Program of British Columbia (www.vch.ca/bmt).

\section{This article has been peer reviewed.}

From the Leukemia/Bone Marrow Transplantation Program of British Columbia, Division of Hematology, St. Paul's Hospital (Léger), Vancouver General Hospital (Nevill), the British Columbia Cancer Agency (Nevill) and the University of British Columbia (Léger, Nevill), Vancouver, BC

Competing interests: None declared.

Contributors: Chantal Léger was responsible for conception of the review, writing and design of various components of the manuscript, and revisions of the article for publication. Tom Nevill provided substantive input on subsequent drafts, assisted in revising the article and redesigning the boxes and the line drawing, and provided photographs. Both authors critically reviewed the article for intellectual content and approved the final version.

Acknowledgement: We thank Shawna Moore for her work on the line drawing.

\section{References}

1. Santos GW. Bone marrow transplantation. In: Stollerman GH, editor. Advances in internal medicine. Chicago: Year Book Publishers; 1975. p. 157-82.

2. Lorenz E, Uphoff DE, Reid TR, Shelton E. Modification of acute irradiation injury in mice and guinea pigs by bone marrow injection. Radiology 1951;58: 863-77.

3. Cohen JA, Vos O, van Bekkum DW. The present status of radiation protection by chemical and biological agents in mammals. In: de Hevesy GC, Forssberg AG, Abbott JD, editors. Advances in radiobiology. Edinburgh: Oliver and Boyd; 1957. p. 134-44.

4. Billingham RE. The biology of graft-versus-host reactions. Harvey Lect 196667;62:21-78

5. Bearman SI, Mori M, Beatty PG, Meyer WG, Buckner CD, Petersen FB, et al. Comparison of morbidity and mortality after marrow transplantation from HLA-genotypically identical siblings and HLA-phenotypically identical unrelated donors. Bone Marrow Transplant 1994;13(1):31-5.

6. Oudshoorn M, van Leeuwen A, vd Zanden HG, van Rood JJ. Bone Marrow Donors Worldwide: a successful exercise in international cooperation. Bone Marrow Transplant 1994;14(1):3-8.

7. Bensinger WI, Price TH, Dale DC, Appelbaum FR, Clift R, Lilleby K, et al The effects of daily recombinant human granulocyte colony-stimulating factor administration on normal granulocyte donors undergoing leukapheresis. Blood 1993;81(7):1883-8

8. Bensinger WI, Martin PJ, Storer B, Clift R, Forman SJ, Negrin R, et al. Transplantation of bone marrow as compared with peripheral-blood cells from HLA-identical relatives in patients with hematologic cancers. $N$ Engl 7 Med 2001;344:175-81.

9. Couban S, Simpson DR, Barnett MJ, Bredeson C, Hubesch L, Howson-Jan $\mathrm{K}$, et al; Canadian Bone Marrow Transplant Group. A randomized multicenter comparison of bone marrow and peripheral blood in recipients of matched 
sibling allogeneic transplants for myeloid malignancies. Blood 2002;100(5): 1525-31.

10. Kurtzberg J, Laughlin M, Graham ML, Smith C, Olson JF, Halperin EC, et al. Placental blood as a source of hematopoietic stem cells for transplantation into unrelated recipients. NEngl 7 Med 1996;335(3):157-66.

11. Gluckman E, Rocha V, Boyer-Chammard A, Locatelli F, Arcese W, Pasquini $\mathrm{R}$, et al. Outcome of cord-blood transplantation from related and unrelated donors. Eurocord Transplant Group and the European Blood and Marrow Transplantation Group. N Engl 7 Med 1997;337(6):373-81.

12. Moller G, editor. Lymphocyte homing. Immunol Rev 1989;108:5-161.

13. Fefer A, Einstein AB, Thomas ED, Buckner CD, Clift RA, Glucksberg H, et al. Bone marrow transplantation for hematologic neoplasia in 16 patients with identical twins. N Engl 7 Med 1974;290(25):1389-93.

14. Clift RA, Buckner CD, Thomas ED, Bensinger WI, Bowden R, Bryant E, et al. Marrow transplantation for chronic myeloid leukemia: a randomized study comparing cyclophosphamide and total body irradiation with busulfan and cyclophosphamide. Blood 1994;84(6):2036-43.

15. Bearman SI, Appelbaum FR, Buckner CD, Petersen FB, Fisher LD, Clift RA, et al. Regimen-related toxicity in patients undergoing bone marrow transplantation. 7 Clin Oncol 1988;6(10):1562-8.

16. Centers for Disease Control and Prevention; Infectious Diseases Society of America; American Society of Blood and Marrow Transplantation. Guidelines for preventing opportunistic infections among hematopoietic stem cell transplant recipients. Biol Blood Marrow Transplant 2000;6:659-734.

17. Andrykowski MA. Psychosocial factors in bone marrow transplantation: a review and recommendations for research. Bone Marrow Transplant 1994;13:357-75.

18. Wolff SN. Second hematopoietic stem cell transplantation for the treatment of graft failure, graft rejection or relapse after allogeneic transplantation. Bone Marrow Transplant 2002;29:545-52.

19. Lum LG. Kinetics of immune reconstitution after human marrow transplantation. Blood 1987;69:369-80.

20. Korngold R, Sprent J. T cell subsets in graft-versus-host disease. In: Burakoff SJ, Deeg HJ, Ferrara J, Atkinson K, editors. Graft-versus-host disease: immunology, pathophysiology, and treatment. New York: Marcel Dekker; 1996. p. 31-50.

21. Przepiorka D, Weisdorf D, Martin P, Klingemann HG, Beatty P, Hows J, et al. Consensus conference on acute GVHD grading. Bone Marrow Transplant $1995 ; 15(6): 825-8$

22. Chao NJ, Deeg HF. In vivo prevention and treatment of graft-versus-host disease. In: Burakoff SJ, Deeg HJ, Ferrara J, Atkinson K, editors. Graft-versushost disease: immunology, pathophysiology, and treatment. New York: Marce Dekker; 1996. p. 639-66.

23. Martin PJ, Hansen JA, Torok-Storb B, Durnam D, Przepiorka D, O'Quigley $\mathrm{J}$, et al. Graft failure in patients receiving T cell-depleted HLA-identical allogeneic marrow transplants. Bone Marrow Transplant 1988;3:445-56.

24. Horowitz MM, Gale RP, Sondel PM, Goldman JM, Kersey J, Kolb HJ, et al. Graft-versus-leukemia reactions after bone marrow transplantation. Blood 1990;75(3):555-62.

25. Nevill TJ, Shepherd JD, Nantel SH, Toze CL, Hogge DE, Sutherland HG, et al. Stem cell transplant-related mortality (TRM) 1985-96: the Vancouver experience [abstract]. Blood 1997;90(Suppl 1):373b.

26. Zittoun RA, Mandelli F, Willemze R, de Witte T, Labar B, Resegotti L, et al. Autologous or allogeneic bone marrow transplantation compared with intensive chemotherapy in acute myelogenous leukemia. European Organization for Research and Treatment of Cancer (EORTC) and the Gruppo Italiano Malattie Ematologiche Maligne dell'Adulto (GIMEMA) Leukemia Cooperative Groups. N Engl 7 Med 1995;332(4):217-23.

27. Schwartzberg LS, Birch R, Hazelton B, Tauer KW, Lee P Jr, Altemose R, et al. Peripheral blood stem cell mobilization by chemotherapy with and without recombinant human granulocyte colony-stimulating factor. 7 Hematother 1992;1(3):317-27.

28. Leger CS, Bredeson C, Kearns B, Bence-Bruckler I, Atkins H, Huebsch L. Autologous blood and marrow transplantation in patients 60 years and older. Biol Blood Marrow Transplant 2000;6(2A):204-10.

29. Weaver CH, Schwartzberg L, Zhen B, Mangum M, Leff R, Tauer K, et al. High-dose chemotherapy and peripheral blood stem cell infusion in patients with non-Hodgkin's lymphoma: results of outpatient treatment in community cancer centers. Bone Marrow Transplant 1997;20:753-60.

30. Shulman HM, Sullivan KM, Weiden PL, McDonald GB, Striker GE, Sale $\mathrm{GE}$, et al. Chronic graft-versus-host syndrome in man. A long-term clinicopathologic study of 20 Seattle patients. Am 7 Med 1980;69(2):204-17.

31. Roy V, Ochs L, Weisdorf D. Late infections following allogeneic bone marrow transplantation: suggested strategies for prophylaxis. Leuk Lymphoma 1997;26:1-15.

32. Sullivan KM, Witherspoon RP, Storb R, Deeg HJ, Dahlberg S, Sanders JE, et al. Alternating-day cyclosporine and prednisone for the treatment of highrisk chronic graft-v-host disease. Blood 1988;72(2):555-61.
33. Storek J, Joseph A, Espino G, Dawson MA, Douek DC, Sullivan KM, et al. Immunity of patients surviving 20 to 30 years after allogeneic or syngeneic bone marrow transplantation [published erratum appears in Blood 2002;99(5):1511]. Blood 2001;98(12):3505-12.

34. Atkinson K, Farewell V, Storb R, Tsoi MS, Sullivan KM, Witherspoon RP et al. Analysis of late infections after human marrow transplantation: role of non-specific suppressor cells in patients with chronic graft-versus-host disease. Blood 1982;60(3):714-20.

35. Han CS, Miller W, Haake R, Weisdorf D. Varicella zoster infection after bone marrow transplantation: incidence, risk factors, and complications. Bone Marrow Transplant 1994;13(3):277-83.

36. Ormrod D, Goa K. Valacyclovir: a review of its use in the management of herpes zoster. Drugs 2000;59:1317-40.

37. Meyers JD, Fluornoy N, Thomas ED. Cytomegalovirus infection and specific cell-mediated immunity after marrow transplant. F Infect Dis 1980;142(6):816-24.

38. Tuan IZ, Dennison D, Weisdorf DJ. Pneumocystis carinii pneumonitis following bone marrow transplantation. Bone Marrow Transplant 1992;10(3):267-72.

39. Pauksen K, Hammarstrom V, Ljungman P, Sjolin J, Oberg G, Lonnerholm $\mathrm{G}$, et al. Immunity to poliovirus and immunization with inactivated poliovirus vaccine after autologous bone marrow transplantation. Clin Infect Dis 1994;18 (4):547-52.

40. Ljungman P, Wiklund-Hammarsten M, Duraj V, Hammarstrom L, Lonnqvist B, Paulin T, et al. Responses to tetanus toxoid immunization after allogeneic bone marrow transplantation. F Infect Dis 1990;162:496-500.

41. Sanders JE, Buckner CD, Leonard JM, Sullivan KM, Witherspoon RP, Deeg $\mathrm{HJ}$, et al. Late effects on gonadal function of cyclophosphamide, total body irradiation, and marrow transplantation. Transplantation 1983;36(3):252-5.

42. Sanders JE, Hawley J, Levy W, Gooley T, Buckner CD, Deeg HJ, et al Pregnancies following high-dose cyclophosphamide with or without highdose busulfan or total-body irradiation and bone marrow transplantation. Blood 1996;87(7):3045-52.

43. Anserini P, Chiodi S, Spinelli S, Costa M, Conte N, Copello F, et al. Semen analysis following allogeneic bone marrow transplantation. Additional data for evidence-based counseling. Bone Marrow Transplant 2002;30(4):447-51.

44. Grigg AP, McLachlan R, Zaja J, Szer J. Reproductive status in long-term bone marrow transplant survivors receiving busulfan-cyclophosphamide (120 mg/kg). Bone Marrow Transplant 2000;26(10):1089-95.

45. Schimmer AD, Quatermain M, Imrie K, Ali V, McCrae J, Stewart AK, et al. Ovarian function after autologous bone marrow transplantation. 7 Clin Oncol 1998;16(7):2359-63.

46. Curtis RE, Rowlings PA, Deeg HJ, Shriner DA, Socie G, Travis LB, et al. Solid cancers after bone marrow transplantation. N Engl F Med 1997;336(13):897-904.

47. Socie G, Stone JV, Wingard JR, Weisdorf D, Henslee-Downey PJ, Bredeson $\mathrm{C}$, et al. Long-term survival and late deaths after allogeneic bone marrow transplantation. Late Effects Working Committee of the International Bone Marrow Transplant Registry. N Engl J Med 1999;341(1):14-21.

48. Forrest DL, Nevill TJ, Naiman SC, Le A, Brockington DA, Barnett MJ, et al. Second malignancy following high-dose therapy and autolgous stem cell transplantation: incidence and risk factor analysis. Bone Marrow Transplant 2003;32(9):915-23.

49. Lavoie J, Connors J, Smith C, Voss NG, Reece DE, Philips GL. Ten-year follow-up of the first 100 patients having received high-dose chemotherapy and autologous stem cell transplantation for primary refractory or relapsed Hodgkin's disease in Vancouver: long-term complications and causes of death [abstract]. Blood 2003;102:116.

50. Chao NJ, Tierney DK, Bloom JR, Long GD, Barr TA, Stallbaum BA, et al. Dynamic assessment of quality of life after autologous bone marrow transplantation. Blood 1992;80(3):825-30.

51. Andrykowski MA, Henslee PJ, Farrall MG. Physical and psychological functioning of adult survivors of allogeneic bone marrow transplantation. Bone Marrow Transplant 1989;4:75-81.

52. Long GD, Laughlin M, Madan B, Kurtzberg J, Gasparetto C, Morris A, et al Unrelated cord blood transplantation in adult patients. Biol Blood Marrow Transplant 2003;9(12):772-80

53. Giralt S, Estey E, Albitar M, van Besien K, Rondon G, Anderlini P, et al. Engraftment of allogeneic hematopoietic progenitor cells with purine analogcontaining chemotherapy: harnessing graft-versus-leukemia without myeloablative therapy. Blood 1997;89(12):4531-6.

Correspondence to: Dr. Chantal S. Léger, 440-1144 Burrard St., Vancouver BC V6Z 2A5; fax 604 684-5707;

cleger@providencehematology.com 